\title{
Neuroendocrine stress response: implications for cardiac surgery-associated acute kidney injury
}

\author{
J. Mauricio Del Rio, Alina Nicoara, Madhav Swaminathan
}

Department of Anesthesiology, Division of Cardiothoracic Anesthesiology and Critical Care Medicine, Duke University Health System, Durham, NC, USA

\begin{abstract}
Surgical stress causes biochemical and physiologic perturbations of every homeostatic axis. These alterations include volume/baroreceptor regulation, sympathetic activation, parasympathetic suppression, neuroendocrine activation, acute phase response protein synthesis and secretion, immune response modulation and long-term behavioral adaptation. The kidney is central to the stress response because of its main role in the maintenance of water, electrolyte balance and hence, intracellular and extracellular compartments, including the intravascular volume. Acute kidney injury after cardiac surgery occurs as a result of numerous factors including ischemia-reperfusion, inflammation, oxidative stress, neurohormonal activation, metabolic factors, and nephrotoxicity or pigment nephropathy. The neuroendocrine stress response has a central role in initiating renal injury during cardiac surgery through an increased release of argininevasopressin and activation of the sympathetic nervous system and the intrarenal and systemic reninangiotensin-aldosterone system. The contribution of an exaggerated neuroendocrine stress response to cardiac surgery and cardiopulmonary bypass as key pathophysiologic mechanism for acute kidney injury after cardiac surgery represents an opportunity for scientific exploration.
\end{abstract}

Keywords: surgical stress, neuroendocrine, acute kidney injury, cardiac surgery

\section{Introduction}

The stress response facilitates physiological and metabolic adjustments required to endure challenges to the physiological balance (homeostasis) [1]. Surgical stress causes biochemical and physiologic perturbations of every homeostatic axis (Table 1) [2]. These alterations include volume/baroreceptor regulation, sympathetic activation, parasympathetic suppression, neuroendocrine activation, acute phase response protein synthesis and secretion, immune response mo-

Address for correspondence:

Alina Nicoara, MD

Box 3094 DUMC / 5691-F HAFS Bldg. Duke University Medical Center

Durham, NC 27710, USA

E-mail: alina.nicoara@duke.edu dulation and long-term behavioral adaptation [3]. The goal of stress response is homeostatic preservation and survival; it sustains cardiovascular homeostasis by maintaining volume and perfusion to key organ systems [1]. Other consequences of stress response are the mobilization of substrates for energy production, and shifting of metabolic pathways from anabolism towards limitation of tissue damage and subsequent repair [1, $4,5]$. The kidney is central to the stress response because of its main role in the maintenance of water, electrolyte balance and hence, intracellular and extracellular compartments, including intravascular volume $[2,4]$.

The interactions between the stress response system, renal mechanisms, inflammatory pathways, and the immune system can have an effect in both adaptation to injury and the pathogenesis of cardiovascular disease [6-8]. 
Table 1. Hormonal changes during surgery (from [4]. Burton D, Nicholson G, Hall G. Endocrine and metabolic response to surgery. Contin Educ Anaesth Crit Care Pain 2004; 4: 144-147, with permission)

\begin{tabular}{|lllll|}
\hline & Pituitary & Adrenal & Pancreatic & Others \\
\hline Increased secretion & $\begin{array}{l}\text { Growth hormone } \\
\text { Adrenocorticotropic hormone } \\
\beta \text { - endorphin } \\
\text { Prolactin } \\
\text { Arginine-vasopressin }\end{array}$ & $\begin{array}{l}\text { Catecholamines } \\
\text { Cortisol } \\
\text { Aldosterone }\end{array}$ & Glucagon & Renin \\
& $\begin{array}{l}\text { Thyroid stimulating hormone } \\
\text { Luteinizing hormone } \\
\text { Unchanged secretion }\end{array}$ & & \\
& Follicle stimulating hormone & & \\
Decreased secretion & & Insulin & Testosterone \\
& & & $\begin{array}{l}\text { Estrogen } \\
\text { Tri- iodothyronine }\end{array}$ \\
\hline
\end{tabular}

\section{Neuroendocrine stress response and fluid balance during cardiac surgery}

Disruption of homeostasis during surgery results in the activation of two main systems of the neuroendocrine stress response: the hypothalamic-pituitary axis (HPA) and the sympathetic nervous system (SNS). Both systems are important components of stress adaptation and interact synergistically. Two major effectors of the neuroendocrine stress response are the renin-angiotensin-aldosterone (RAAS) and the arginine-vasopressin (AVP) systems.

Hypothalamic-Pituitary-Adrenal (HPA) Axis. The HPA axis is perhaps the single most important stress response system. It meets the demands of stress mostly through the synthesis and release of three key hormones, corticotrophin-releasing hormone $(\mathrm{CRH})$ from the hypothalamus, adrenocorticotropin hormone (ACTH) from the pituitary gland, and cortisol from the adrenal glands (Figure 1) [1].

Multiple external and internal stimuli activate neurons in the paraventricular hypothalamic nucleus to synthesize and secrete $\mathrm{CRH}$, which plays a pivotal role in the response to stress. The presence of $\mathrm{CRH}$ and its receptors in other brain areas and in other organs such as skin, heart and gastrointestinal tract suggests a more complex role of $\mathrm{CRH}$ in the stress response, beyond the HPA axis [1].

Once in the peripheral circulation, ACTH is transported to the adrenal cortex, where it induces glucocorticoids -mainly cortisol -synthesis and is released in the zone fasciculata. Glucocorticoids have a global effect on homeostasis and in most organ systems. Glucocorticoids apply feedback on the hypothalamus and pituitary gland, inhibiting further secretion of $\mathrm{CRH}$ and ACTH. However, during periods of prolonged stress, feedback inhibition does not occur, resulting in excessive glucocorticoids levels. ACTH production is usually far in excess than is required for maximum

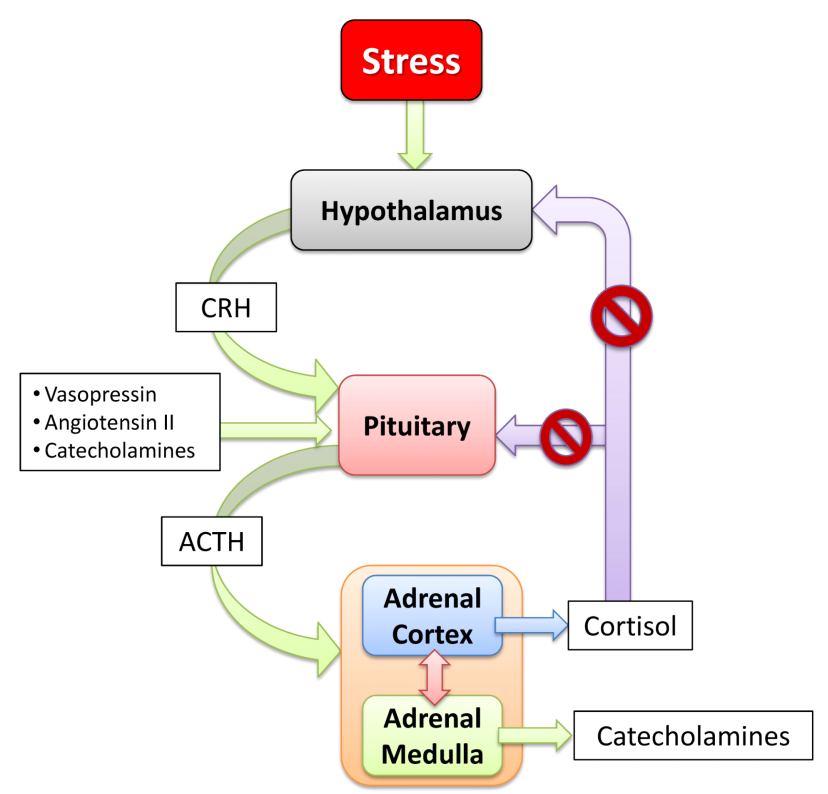

Fig 1. The hypothalamic-pituitary-adrenal (HPA) axis. Critical hormones that constitute the HPA axis are shown. Purple arrows indicate negative feedback pathways

adrenocortical response [4]. The condition in which stress-induced ACTH and glucocorticoid hypersecretion fail to inhibit additional pituitary ACTH secretion is called "permissive facilitation" [9]. ACTH is not the only regulator of cortisol production. Other factors such as angiotensin, vasopressin and direct sympathetic adrenal cortex innervation influence glucocorticoid secretion.

Glucocorticoid production can increase immediately after surgical insult; cortisol blood concentration can reach up to four- to five-fold the normal baseline value within a few hours of starting major surgery. The magnitude and duration of cortisol increase correlates with the severity of surgical insult. The major role of glucocorticoids is in carbohydrate metabolism and 
mobilization of energy stores. However, cortisol also has a mild mineralocorticoid action resulting in sodium retention and hypokalemia if high plasma concentrations are sustained for prolonged periods of time [10].

Stress induced CRH and ACTH secretion also stimulates the production of aldosterone, which has a more potent mineralocorticoid effect than cortisol [10]. Sustained adrenal cortex stimulation by ACTH has different effects on mineralocorticoids and glucocorticoids. After several hours, aldosterone production begins to wane and normal or low levels of aldosterone are found within 24 hours [10]. However, RAAS stimulation induces sustained higher concentrations of aldosterone.

Sympathetic Nervous System. SNS activation results in increased catecholamine secretion from the adrenal medulla into the peripheral tissues. There is a close anatomic and physiologic relationship between HPA and SNS because the adrenal medulla is developed inside the adrenal cortex, where catecholamineglucocorticoid interaction occurs. In response to surgical stress, epinephrine response parallels HPA stimulation while norepinephrine shows local variability [3]. Marked catecholamine concentration increases have been demonstrated in patients undergoing cardiac surgery with a cardiopulmonary bypass (CPB) [11].

Catecholamine responses have two temporal sequences. Short-term effects occur within minutes, whereas long-term effects last days. Short-term effects reflect rapid changes in target proteins functional state caused primarily by phosphorylation events. Long-term effects result from changes in the gene expression pattern [3].

Renal sympathetic activation stimulates sodium reabsorption through direct nerve stimulation and indirectly by plasma catecholamines. The result is renin release and intra-renal blood flow distribution to the juxta-medullary nephrons. Renin release from the juxtaglomerular cells results in the conversion of angiotensin I to angiotensin II (Figure 2). Angiotensin II stimulates aldosterone secretion from the adrenal cortex. In contrast to the release of aldosterone through ACTH stimulation, which is short-lived, aldosterone response to angiotensin II is sustained and continues as long as the angiotensin II level persist to be elevated.

Renin-Angiotensin-Aldosterone System. The RAAS is essential in regulating sodium excretion during acute and chronic stress through the following pathways: 1) Increased angiotensin II local production, which increases proximal tubule sodium reabsorption by efferent arteriolar vasoconstriction, 2) increased angiotensin II plasma levels causing renal tubular sodium reabsorption independently of aldosterone, and 3) stimulation of aldosterone secretion. Angiotensin II restores extracellular fluid volume not only by

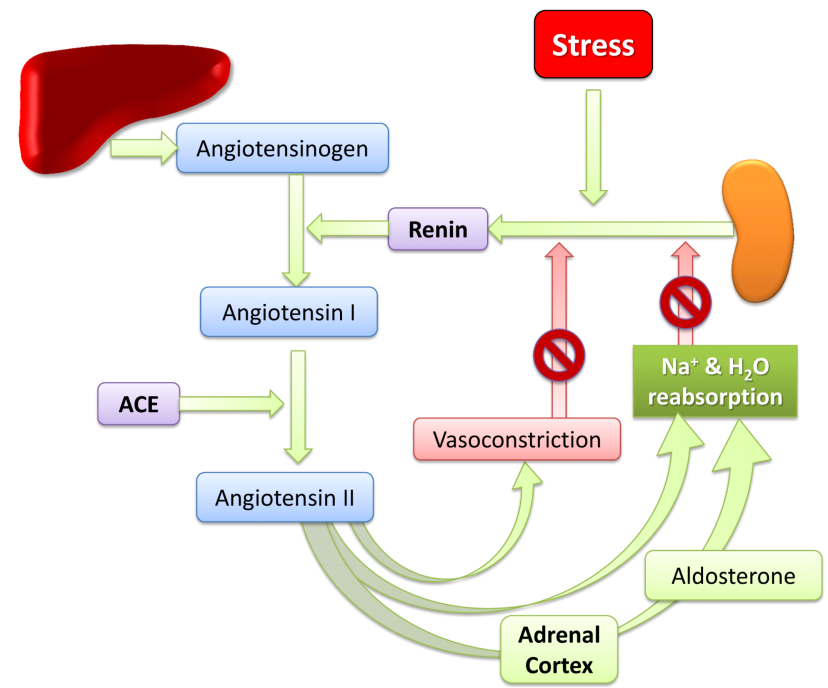

Fig 2. The renin-angiotensin-aldosterone system (RAAS). Critical components of the RAAS are shown. Central to the system are the renal release of renin and the hepatic production of angiotensinogen that leads to formation of angiotensin II (AGII). The resulting effects of AGII - vasoconstriction, sodium and water reabsorption, and aldosterone production - also exert a negative feedback effect on renal release of renin

stimulating aldosterone, but also by vasoconstriction, modulating systemic arterial and renal perfusion pressure. Angiotensin II by itself has an inhibitory effect on renin release and increases catecholamine secretion from the adrenal medulla [10].

Arginine-Vasopressin. Surgical stress increases AVP release by nociceptive pathway stimulation, hypoxia, nausea and emesis [10]. Increased AVP release from the posterior pituitary may act synergistically with CRH and stimulates ACTH and $\beta$-endorphin production. Surgery with CPB is associated with increased AVP levels followed by a gradual return to baseline postoperatively $[12,13]$.

\section{The role of neuroendocrine stress response in cardiac surgery-associated acute kidney injury (AKI)}

Acute kidney injury (AKI) after cardiac surgery increases morbidity and mortality affecting long-term outcomes [14-16]. Patient-related risk factors interact with $\mathrm{CPB}$ exposure contributing to the development of cardiac surgery-associated AKI (CSA-AKI) [17]. In particular, risk prediction models identify $\mathrm{CPB}$ duration as an important risk factor for CSA-AKI [18, 19].

\section{CSA-AKI pathophysiology}

The pathophysiology of CSA-AKI is multifactorial and at least six processes play a role: Ischemia- 
reperfusion, inflammation, oxidative stress, neurohormonal activation, metabolic factors, and nephrotoxicity/ pigment nephropathy [20]. These processes interact in a complex manner with renal blood flow and vasoregulation alterations, systemic inflammatory response and the generation of microemboli contributing to pathogenesis [21,22].

AKI initiation and neuroendocrine stress response activation

The neuroendocrine stress response has a central role in initiating renal injury during cardiac surgery. AKI is provoked by an absolute or relative decrease in renal perfusion that decreases the glomerular filtration rate (GFR). There are early compensatory mechanisms attempting to correct the renal blood flow (RBF) and GFR [20, 23]. First, an intrinsic renal autoregulatory mechanism is mediated by a glomerular afferent arteriole myogenic response [24]. The afferent arteriole vasodilates in response to decreased renal perfusion pressure. The tubulo-glomerular feedback (TGF) mechanism alters GFR by increasing glomerular vascular resistance in response to elevation in sodium chloride concentration at the macula densa. The TGF mechanism complements the autoregulatory process that aims to stabilize GFR and fluid concentration delivery to the distal nephron $[2,10,20,24]$. Next, there is a simultaneous systemic response to hypoperfusion by SNS \& RAAS activation, and AVP release. The net effect is increased tubular absorption to improve RBF and GFR, generalized vasoconstriction and RAAS up-regulation in an attempt to normalize systemic blood pressure. The use of urinary angiotensinogen as an index of the intrarenal RAAS activity has been investigated and a recent study has showed that elevated urinary angiotensinogen has been associated with the development of AKI after cardiac surgery [25]. Low-dose $(0.025 \mathrm{mcg} / \mathrm{kg} / \mathrm{min})$ human atrial natriuretic peptide, a potent natriuretic, diuretic and vasodilatory peptide, could reduce the incidence of postoperative AKI by preventing an increase in the activity of intrarenal but not the systemic RAAS [26].

Finally, unrestricted renal vasoconstriction is counterbalanced by the activation of local intrarenal, and systemic vasodilatory systems (mediated by prostaglandins and nitric oxide) opposing the vasoconstrictive effects of angiotensin II and renal adrenergic activity $[10,20]$. The initial balance between vasoconstrictors and vasodilators conserves RBF and GFR at the expense of water and urea resorption mediated by AVP $[10,20]$.

AKI perpetuation and the role of persistent neuroendocrine activation

The process that extends the initial injury is not completely understood, but is characterized by a progressive decline in GFR after renal perfusion recovery [20, 23]. CPB may constitute a key event in the progression of the initial insult into the extension phase of AKI. Following CPB initiation, RBF is decreased from $25 \%$ of the total cardiac output to only $12-13 \%$, reflecting a $30 \%$ decrease in the effective renal perfusion. RBF during CPB becomes dependent on the pump flow [27]. It is not clear if there is autoregulatory reflex preservation $[22,28]$. CPB alters renal perfusion regulation by severely decreasing medullary renal $\mathrm{PO}_{2}$ regardless of mean arterial pressure and pump flows [28]. There are indications that the lack of pulsatile flow during CBP contributes to altered renal perfusion and increased neuroendocrine response. Studies of pulsatile CPB show decreased levels of inflammatory mediators and vasodilators [29-31]. However, effects in morbidity and mortality are inconclusive.

During the progression of renal insult, autoregulatory mechanisms that were effective at first are unable to compensate, causing further RBF and GFR impairment [20]. The inappropriate renal vasoconstriction mediated by SNS and RAAS stimulation adds to the presence of leukotrienes, thromboxanes and endothelin causing an exaggerated vasoconstrictive renal vascular response [32-34]. Additionally, the renal vascular endothelium is over-sensitized to vasoconstrictors and poorly responsive to vasodilators due to the excessive availability of intracellular calcium [34]. The use of vasodilators and restoration of RBF does not reverse this state indicating that vasodilator / vasoconstrictor imbalance is not the only mechanism of injury extension.

The possible maladaptive role of stress response to surgical injury is highlighted by the fact that increased plasmatic catecholamines concentration causes adrenoreceptor downregulation with desensitizationmediated vasodilatory shock. In particular abnormally elevated cathecolamines can predispose to increased occurrence, severity and duration of AKI in cardiac surgical patients with COMT (cathecol-O-methyltransferase) gene polymorphism causing a decreased degradation of catecholamines [35]. Assessment of adrenergic genetic variants, with low versus high enzymatic activity, may provide additional insight into the individual risk assessment for AKI after cardiac surgery [36].

\section{Pathophysiologic consequences of AKI extension}

Tubular cellular injury. Renal injury extension is caused by tubular epithelial cell damage and vascular endothelial activation. The tubular cellular injury is characterized by the apical brush border loss, basal membranes disruption, intercellular junction damage causing tubular functional loss [37, 38]. Injured tubular epithelial cells produce adhesion molecules and 
chemokines that attract cells eliciting further local inflammation. Tubular cell loss and mechanical tubular obstruction have a less important role.

Endothelial injury. The mechanism of initial renal endothelial damage is ischemia-reperfusion [20, 23]. Endothelial injury causes renal autoregulation loss, sensitivity to vasoconstrictors, and blunted response to nitric oxide with further renal perfusion impairment and tubular injury [32-34]. Cortico-medullary junction and outer medulla nephrons are the most susceptible $[20,22,23]$. The final consequences are altered barrier function, increased vascular permeability, increased interstitial edema and further blood flow decrease. There is no specific pharmacologic therapy to improve renal function or to prevent the occurrence of CSAAKI.

\section{Other contributors to CSA-AKI}

Local and systemic inflammatory response. Renal tubular epithelial cells have dual roles as triggers and targets of inflammation. The local inflammatory activation of tubular cells adds to the systemic inflammatory response generated by $\mathrm{CPB}$ and surgical stress [20]. The contact of blood components with CPB circuit surface results in the release of cytokines and proinflammatory mediators including, tumor necrosis factor- $\alpha$ (TNF- $\alpha$ ), interleukin-6 (IL-6), and interleukin8 (IL-8) which are mediators of renal insult. Upregulation of the inflammatory cascade contributes to the tubular damage extending to the vascular epithelium. The inflammatory reaction also contributes to ischemiareperfusion injury [21, 22, 39].
Ischemia-reperfusion. Decreased cardiac output, low renal perfusion, embolism, and exogenous catecholamines lead to ischemia-reperfusion injury. Such injury contributes to high-energy cellular phosphate depletion, calcium accumulation, oxygen-free radical generation, leukocytes activation, and nuclear factor$\kappa \beta(N F-\kappa \beta)$ activation. In turn, NF- $\kappa \beta$ mediates further local renal cytokines release with inflammatory cascade amplification. The final result is tubular and endothelial cellular necrosis and apoptosis [22, 23].

$C P B$ direct nephrotoxicity. Exposure to $\mathrm{CPB}$ induces hemolysis and complement activation resulting in increased free erythrocyte components circulating. The presence of pigments such as hemoglobin, free iron and myoglobin cause scavengers (i.e. transferrin and haptoglobin) consumption. Those free molecules bind to nitric oxide and can have direct vasoconstrictor effects, altering systemic vascular resistance and platelet function. Such substances also can cause tubular obstruction contributing to direct nephrotoxicity and CSA-AKI occurrence [40].

\section{Future directions}

Numerous factors including, reduced renal perfusion pressure, activation of inflammatory mediators, and direct nephrotoxicity interact in the pathogenesis of CSA-AKI (Figure 3). However, the contribution of an exaggerated neuroendocrine stress response to cardiac surgery and $\mathrm{CPB}$ as the key pathophysiologic mechanism for CSA-AKI represents an opportunity

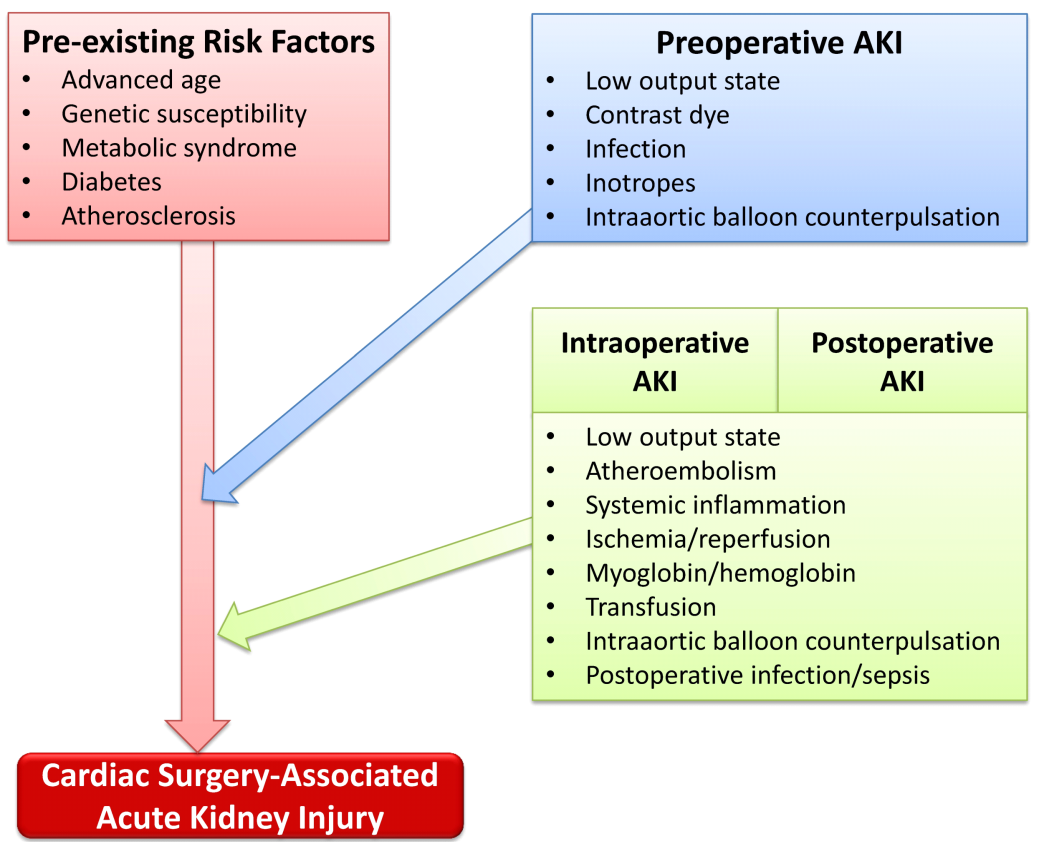

Fig 3. Relationship of perioperative clinical risk factors for cardiac surgery - associated acute kidney injury. (adapted from [22]. Stafford-Smith M, Patel UD, Phillips-Bute BG, Shaw AD, Swaminathan M. Acute kidney injury and chronic kidney disease after cardiac surgery Adv Chronic Kidney Dis 2008; 15: 257-277, with permission) 
for scientific exploration. The role of a "maladaptive" response to chronic stress in the pathogenesis of cardiovascular disease is a novel pathway for research.

\section{Conflict of interest}

Nothing to declare

\section{References}

1. Miller DB, O'Callaghan JP. Neuroendocrine aspects of the response to stress. Metabolism 2002; 51(6 Suppl 1): 5-10

2. Desborough JP. The stress response to trauma and surgery. Br J Anaesth 2000; 85: 109-117

3. Udelsman R, Holbrook NJ. Endocrine and molecular responses to surgical stress. Curr Probl Surg 1994; 31: 653-720

4. Burton D, Nicholson G, Hall G. Endocrine and metabolic response to surgery. Contin Educ Anaesth Crit Care Pain 2004; 4: 144 147. DOI: $10.1093 / \mathrm{bjaceaccp} / \mathrm{mkh} 040$

5. Giannoudis PV, Dinopoulos H, Chalidis B, Hall GM. Surgical stress response. Injury 2006; 37 Suppl 5: S3-9. DOI: 10.1016/ S0020-1383(07)70005-0

6. Luft FC, Dechend R, Müller DN. Immune mechanisms in angiotensin II-induced target-organ damage. Ann Med 2012; 44 Suppl 1: S49-54. DOI: 10.3109/07853890.2011.653396

7. Saavedra JM, Sánchez-Lemus E, Benicky J. Blockade of brain angiotensin II AT1 receptors ameliorates stress, anxiety, brain inflammation and ischemia: Therapeutic implications. Psychoneuroendocrinology 2011; 36: 1-18. DOI: 10.1016/ j.psyneuen.2010.10.001

8. Mayorov DN. Brain angiotensin AT1 receptors as specific regulators of cardiovascular reactivity to acute psychoemotional stress. Clin Exp Pharmacol Physiol 2011; 38: 126-135. DOI: 10.1111/j.1440-1681.2010.05469.x

9. Gann DS, Cryer GL, Pirkle JC Jr. Physiological inhibition and facilitation of adrenocortical response to hemorrhage. Am J Physiol 1977; 232: R5-9

10. Espiner EA. The effects of stress on salt and water balance. Baillieres Clin Endocrinol Metab 1987; 1: 375-390

11. Reves JG, Karp RB, Buttner EE, Tosone S, Smith LR, Samuelson $\mathrm{PN}$, et al. Neuronal and adrenomedullary catecholamine release in response to cardiopulmonary bypass in man. Circulation 1982; 66: 49-55. DOI: 10.1161/01.CIR.66.1.49

12. Holt NF, Haspel KL. Vasopressin: a review of therapeutic applications. J Cardiothorac Vasc Anesth 2010; 24: 330-347. DOI: $10.1053 /$ j.jvca.2009.09.006

13. Kuitunen A, Hynynen M, Salmenperä M, Rasi V, Järvinen A, Scheinin M, et al. Anaesthesia affects plasma concentrations of vasopressin, von Willebrand factor and coagulation factor VIII in cardiac surgical patients. Br J Anaesth 1993; 70: 173-180

14. Chertow GM, Levy EM, Hammermeister KE, Grover F, Daley J. Independent association between acute renal failure and mortality following cardiac surgery. Am J Med 1998; 104: 343348. DOI: $10.1016 / \mathrm{S} 0002-9343(98) 00058-8$

15. Conlon PJ, Stafford-Smith M, White WD, Newman MF, King S, Winn MP, et al. Acute renal failure following cardiac surgery. Nephrol Dial Transplant 1999; 14: 1158-1162

16. Mangano CM, Diamondstone LS, Ramsay JG, Aggarwal A, Herskowitz A, Mangano DT. Renal dysfunction after myocardial revascularization: risk factors, adverse outcomes, and hospital resource utilization. The Multicenter Study of Perioperative Ischemia Research Group. Ann Intern Med 1998; 128: 194203. DOI: $10.7326 / 0003-4819-128-3-199802010-00005$

17. Wesselink RM, de Boer A, Morshuis WJ, Leusink JA. Cardiopulmonary-bypass time has important independent influence on mortality and morbidity. Eur J Cardiothorac Surg 1997; 11: 1141-1145. DOI: 10.1016/S1010-7940(97)01217-7

18. Palomba H, de Castro I, Neto AL, Lage S, Yu L. Acute kidney injury prediction following elective cardiac surgery: AKICS Score. Kidney Int 2007; 72: 624-631. DOI: 10.1038/sj.ki.5002419

19. Wijeysundera DN, Karkouti K, Dupuis JY, Rao V, Chan CT, Granton JT, et al. Derivation and validation of a simplified predictive index for renal replacement therapy after cardiac surgery. JAMA 2007; 297: 1801-1809. DOI: 10.1001/ jama.297.16.1801

20. Garwood S. Cardiac surgery-associated acute renal injury: new paradigms and innovative therapies. J Cardiothorac Vasc Anesth 2010; 24: 990-1001. DOI: 10.1053/j.jvca.2010.05.010

21. Hudson C, Hudson J, Swaminathan M, Shaw A, Stafford-Smith M, Patel UD. Emerging concepts in acute kidney injury following cardiac surgery. Semin Cardiothorac Vasc Anesth 2008; 12: 320330. DOI: $10.1177 / 1089253208328582$

22. Stafford-Smith M, Patel UD, Phillips-Bute BG, Shaw AD, Swaminathan M. Acute kidney injury and chronic kidney disease after cardiac surgery. Adv Chronic Kidney Dis 2008; 15: 257277. DOI: $10.1053 /$ j.ackd.2008.04.006

23. Rosner MH, Portilla D, Okusa MD. Cardiac surgery as a cause of acute kidney injury: pathogenesis and potential therapies. J Intensive Care Med 2008; 23: 3-18. DOI: 10.1177/ 0885066607309998

24. Walker M $3^{\text {rd }}$, Harrison-Bernard LM, Cook AK, Navar LG. Dynamic interaction between myogenic and TGF mechanisms in afferent arteriolar blood flow autoregulation. Am J Physiol Renal Physiol 2000; 279: F858-865

25. Alge JL, Karakala N, Neely BA, Janech MG, Tumlin JA, Chawla LS, et al. Urinary angiotensinogen and risk of severe AKI. Clin J Am Soc Nephrol 2013; 8: 184-193. DOI: 10.2215/ CJN.06280612

26. Moriyama T, Hagihara S, Shiramomo T, Nagaoka M, Iwakawa S, Kanmura Y. The protective effect of human atrial natriuretic peptide on renal damage during cardiac surgery. J Anesth 2016. [Epub ahead of print]. DOI: 10.1007/s00540-016-2284-0

27. Andersson LG, Bratteby LE, Ekroth R, Hallhagen S, Joachimsson $\mathrm{PO}$, van der Linden J, et al. Renal function during cardiopulmonary bypass: influence of pump flow and systemic blood pressure. Eur J Cardiothorac Surg 1994; 8: 597-602. DOI: 10.1016/10107940(94)90043-4

28. Stafford-Smith M, Grocott HP. Renal medullary hypoxia during experimental cardiopulmonary bypass: a pilot study. Perfusion 2005; 20: 53-58. DOI: 10.1191/0267659105pf780oa

29. Aranki SF, Fitzgerald DJ, D'Ambra MN. Prophylactic pulsatile cardiopulmonary bypass in the elderly - stress response reduction at what cost? Crit Care Med 2009; 37: 1142-1143. DOI: 10.1097/CCM.0b013e31819872a5

30. Murkin JM, Martzke JS, Buchan AM, Bentley C, Wong CJ. A randomized study of the influence of perfusion technique and $\mathrm{pH}$ management strategy in 316 patients undergoing coronary artery bypass surgery. I. Mortality and cardiovascular morbidity. J Thorac Cardiovasc Surg 1995; 110: 340-348. DOI: 10.1016/ S0022-5223(95)70229-6

31. Onorati F, Santarpino G, Presta P, Caroleo S, Abdalla K, Santangelo E, et al. Pulsatile perfusion with intra-aortic balloon 
pumping ameliorates whole body response to cardiopulmonary bypass in the elderly. Crit Care Med 2009; 37: 902-911. DOI: 10.1097/CCM.0b013e3181962aa9

32. Conger JD, Robinette JB, Schrier RW. Smooth muscle calcium and endothelium-derived relaxing factor in the abnormal vascular responses of acute renal failure. J Clin Invest 1988; 82: 532537. DOI: $10.1172 / \mathrm{JCI} 113628$

33. Kelleher SP, Robinette JB, Conger JD. Sympathetic nervous system in the loss of autoregulation in acute renal failure. Am J Physiol 1984; 246(4 Pt 2): F379-386

34. Robinette JB, Conger JD. Angiotensin and thromboxane in the enhanced renal adrenergic nerve sensitivity of acute renal failure. J Clin Invest 1990; 86: 1532-1539. DOI: 10.1172/JCI114872

35. Haase-Fielitz A, Haase M, Bellomo R, Lambert G, Matalanis G, Story D, et al. Decreased catecholamine degradation associates with shock and kidney injury after cardiac surgery. J Am Soc Nephrol 2009; 20: 1393-1403. DOI: 10.1681/ASN.2008080915

36. Albert C, Kube J, Haase-Fielitz A, Dittrich A, Schanze D, Zenker $\mathrm{M}$, et al. Pilot study of association of catechol-O-methyl trans- ferase rs4680 genotypes with acute kidney injury and tubular stress after open heart surgery. Biomark Med 2014; 8: 1227 1238. DOI: $10.2217 / \mathrm{bmm} .14 .85$

37. Alejandro VSJ, Nelson WJ, Huie P, Sibley RK, Dafoe D, Kuo P, et al. Postischemic injury, delayed function and $\mathrm{Na}^{+} / \mathrm{K}^{+}$-ATPase distribution in the transplanted kidney. Kidney Int 1995; 48: 1308-1315. DOI: 10.1038/ki.1995.415

38. Kwon O, Nelson WJ, Sibley R, Huie P, Scandling JD, Dafoe D, et al. Backleak, tight junctions, and cell- cell adhesion in postischemic injury to the renal allograft. J Clin Invest 1998; 101 : 2054-2064. DOI: $10.1172 / \mathrm{JCI} 772$

39. Hall RI, Smith MS, Rocker G. The systemic inflammatory response to cardiopulmonary bypass: pathophysiological, therapeutic, and pharmacological considerations. Anesth Analg 1997; 85: $766-782$

40. Haase M, Haase-Fielitz A, Bagshaw SM, Ronco C, Bellomo R. Cardiopulmonary bypass-associated acute kidney injury: a pigment nephropathy? Contrib Nephrol 2007; 156: 340-353. DOI: $10.1159 / 0000102125$ 